(2) OPEN ACCESS

\title{
Intravenous immunoglobulin treatment for mild Guillain-Barré syndrome: an international observational study
}

\author{
Christine Verboon (1), ${ }^{1}$ Thomas Harbo 10 , ${ }^{2}$ David R Cornblath, ${ }^{3}$ \\ Richard A C Hughes (ㅇ, , ${ }^{4}$ Pieter A van Doorn, ${ }^{1}$ Michael P Lunn 이, ${ }^{4}$ \\ Kenneth C Gorson, ${ }^{5}$ Fabio Barroso, ${ }^{6}$ Satoshi Kuwabara (1) , ${ }^{7}$ Giuliana Galassi, ${ }^{8}$ \\ Helmar C Lehmann (10), ${ }^{9}$ Susumu Kusunoki 이, ${ }^{10}$ Ricardo C Reisin, ${ }^{11}$ Davide Binda, ${ }^{12}$ \\ Guido Cavaletti, ${ }^{12}$ Bart C Jacobs (1) , ${ }^{1,13}$ IGOS consortium
}

\begin{abstract}
- Additional supplemental material is published online only. To view, please visit the journal online (http://dx. doi.org/10.1136/jnnp-2020325815).
\end{abstract}

For numbered affiliations see end of article.

\section{Correspondence to} Professor Bart C Jacobs, Neurology and Immunology, Ee2289, Erasmus MC, Rotterdam, Netherlands; $b$. jacobs@erasmusmc.n!

Received 5 December 2020 Revised 6 April 2021

Accepted 11 April 2021

Published Online First 8 June 2021

\section{SLinked}

- http://dx.doi.org/10.1136/ jnnp-2021-326848

\section{Check for updates}

(C) Author(s) (or their employer(s)) 2021. Re-use permitted under CC BY-NC. No commercial re-use. See rights and permissions. Published by BMJ.

To cite: Verboon C, Harbo T, Cornblath DR, et al. J Neurol Neurosurg Psychiatry

2021:92:1080-1088.

\section{ABSTRACT \\ Objective To compare the disease course in patients with mild Guillain-Barré syndrome (GBS) who were treated with intravenous immunoglobulin (IVIg) or supportive care only. \\ Methods We selected patients from the prospective} observational International GBS Outcome Study (IGOS) who were able to walk independently at study entry (mild GBS), treated with one IVIg course or supportive care. The primary endpoint was the GBS disability score four weeks after study entry, assessed by multivariable ordinal regression analysis.

Results Of 188 eligible patients, 148 (79\%) were treated with IVIg and 40 (21\%) with supportive care. The IVIg group was more disabled at baseline. IVIg treatment was not associated with lower GBS disability scores at 4 weeks (adjusted OR (aOR) 1.62, 95\% Cl 0.63 to 4.13). Nearly all secondary endpoints showed no benefit from $\mathrm{IVIg}$, although the time to regain full muscle strength was shorter ( 28 vs 56 days, $p=0.03$ ) and reported pain at 26 weeks was lower $(n=26 / 121,22 \%$ vs $n=12 / 30,40 \%$, $\mathrm{p}=0.04$ ) in the IVIg treated patients. In the subanalysis with persistent mild GBS in the first 2 weeks, the aOR for a lower GBS disability score at 4 weeks was 2.32 (95\% Cl 0.76 to 7.13$)$. At 1 year, $40 \%$ of all patients had residual symptoms.

Conclusion In patients with mild GBS, one course of IVIg did not improve the overall disease course. The certainty of this conclusion is limited by confounding factors, selection bias and wide confidence limits. Residual symptoms were often present after one year, indicating the need for better treatments in mild GBS.

\section{INTRODUCTION}

Approximately $20 \%-40 \%$ of patients with Guillain-Barré syndrome (GBS) do not lose the ability to walk unaided during their disease course, which has been called 'mild GBS'. ${ }^{1-3}$ In contrast to what its name suggests, mild GBS may have an unfavourable clinical course and poor outcome after supportive care alone. Patients who initially have mild GBS can deteriorate later on during the progressive phase of the disease. Dilemmas about whether and when to start treatment arise during the first weeks after onset of GBS because currently it is not possible to predict at presentation who is at risk of further deterioration, while postponing treatment until after further deterioration might result in more severe and possibly irreversible nerve damage. ${ }^{45}$ In addition, the differentiation between mild and severe GBS is based on the GBS disability scale, which is mainly driven by motor function of the legs and ignores involvement of the arms as well as cranial, sensory and autonomic nerves or non-motor function; up to $38 \%$ of mildly affected patients report residual fatigue, pain or persistent neurological deficits after 6 months. ${ }^{6}$

Both plasma exchange (PE) and intravenous immunoglobulin (IVIg) are equally effective in GBS patients who are unable to walk independently (severe GBS). ${ }^{7-10}$ One trial showed that the time to onset of motor recovery in patients still able to walk was shortened after two sessions of $\mathrm{PE},{ }^{1}$ but no randomised controlled trials have been performed to evaluate the efficacy of IVIg in mild GBS. ${ }^{71}$ Reasons not to treat mild GBS patients may include spontaneous recovery in a large proportion of patients due to the self-limiting nature of the disease, side effects including allergic reactions or thromboembolic events, and the fact that IVIg is expensive. ${ }^{12}$

A previous study of patients recruited in the International GBS Outcome Study (IGOS) showed that $75 \%$ of those with mild GBS at entry were treated with IVIg. ${ }^{13}$ We have taken advantage of this variation in current treatment practice to compare the clinical course and outcome in patients with mild GBS treated with either supportive care or supportive care and IVIg.

\section{METHODS}

\section{International GBS Outcome Study}

IGOS is an international, observational, prospective cohort study enrolling patients with GBS from participating centres within 2 weeks of disease onset. ${ }^{14}$ All patients gave written informed consent. 


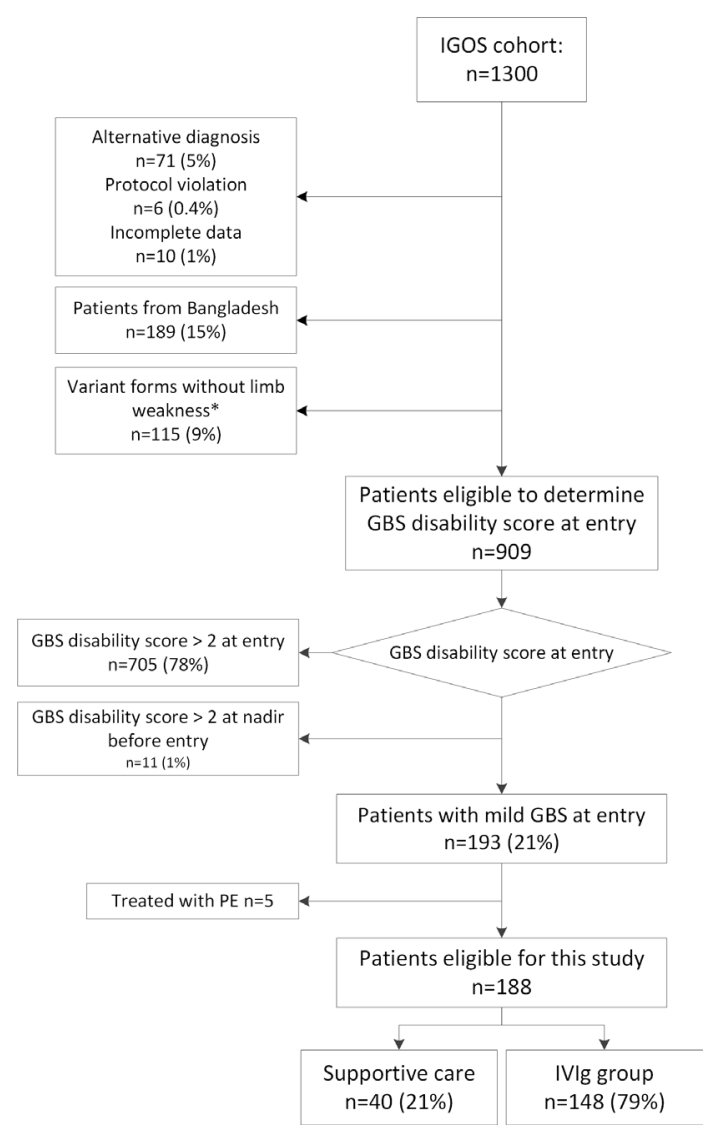

Figure 1 Flow chart study population. *Variant forms without limb weakness ( $n=115)$ : pure MFS: $n=66$; sensory ataxic GBS: $n=24$; other variant forms without limb weakness: $n=25$. GBS, Guillain-Barré syndrome; IGOS, International GBS Outcome Study; IVIg, intravenous immunoglobulin; MFS, Miller Fisher syndrome; PE, plasma exchange

\section{Study population}

From the first 1300 patients enrolled in IGOS (IGOS-1300 cohort), we selected all patients with a GBS disability score of 2 or lower (able to walk independently) at study entry who had been included up until January 2017, with the following exceptions. We excluded patients from low-income countries (ie, Bangladesh) because the current treatment practice differs substantially from other IGOS-participating countries. ${ }^{2}$ We also excluded patients who had Miller Fisher syndrome and other GBS variants without limb weakness because these variant forms may not affect the GBS disability score or the Medical Research Council (MRC) sum score. We also excluded those who were treated with PE only.

We selected patients with mild GBS at presentation because in clinical practice, the dilemma of whether and when to start treatment is most pressing at the time of initial diagnosis.

\section{Patient groups}

We divided patients into those receiving supportive care alone and those receiving supportive care and one standard course of IVIg ( $2 \mathrm{~g} / \mathrm{kg}$ in $2-5$ days) within the first 4 weeks after study entry. Patients who received additional IVIg courses or PE sessions were not excluded.

We first analysed patients with mild GBS at entry. However, this analysis might have included patients who presented early, but were destined to progress to severe GBS. Therefore, to assess the effect of IVIg in patients with truly persistent mild GBS, we conducted a second analysis in the subgroup of patients whose GBS disability score remained 2 or less during the first 2 weeks after study entry.

\section{Assessments}

We prospectively collected data regarding age, gender, reported antecedent events and the following clinical features: cranial nerve involvement, sensory deficits, MRC sum score, ataxia, GBS disability score, GBS clinical variant, and autonomic dysfunction at entry and after 1,2, 4, 8, 13, 26 and 52 weeks. The GBS disability score measures disability, and ranges from 0 (healthy) to 6 (dead). ${ }^{15}$ The MRC sum score measures strength in six bilateral muscle pairs and ranges from 60 (full muscle strength) to 0 (complete paralysis). ${ }^{16}$ The presence of autonomic dysfunction was determined by the treating physician, and was defined as cardiac, blood pressure, gastroenterological, bladder, pupil or other autonomic dysfunction. We classified the first Nerve Conduction Study (NCS) according to Hadden's criteria into the categories demyelinating, axonal, inexcitable, equivocal or normal nerve conduction. ${ }^{17}$ Treatment information included treatment type (IVIg, PE, other), treatment regimen, dates of start and end of treatment and adverse events.

\section{Study endpoints}

The primary endpoint was functional outcome, defined as a lower GBS disability score after 4 weeks in patients treated with one IVIg course compared with patients not treated with IVIg. This endpoint has often been used in previous trials and enables comparisons between studies. ${ }^{711} 1819$ Secondary endpoints were: GBS disability score at 26 weeks, MRC sum score, Rasch-Built Overall Built Disability Score (R-ODS), fatigue severity scale and the EuroQol Visual Analogue Scale at 4 and 26 weeks, time to regain full muscle strength (MRC sum score of 60), time to reach full disability recovery (GBS disability score of 0 ), ${ }^{20}{ }^{21}$ and the frequency of hospital admission, progression to GBS disability score 3 or higher, progression to mechanical ventilation, and the presence of pain and cranial nerve deficits at 4 and 26 weeks. ${ }^{22}$ The R-ODS raw score was transformed into the R-ODS centile metric score to calculate the median R-ODS centile metric. ${ }^{20} \mathrm{~A}$ mild course during the 4 weeks of follow-up was defined as a GBS disability score of 2 or lower at study entry and after 1 , 2 and 4 weeks. The time needed to regain full muscle strength (MRC sum score of 60 points) and full recovery on the GBS disability scale (a score of 0 points) were derived from the study assessment dates. Residual symptoms were defined as the presence of pain (muscle, joint, radicular, neuropathic pain, painful paresthesias), cranial nerve involvement, sensory deficits, ataxia or an MRC sum score $<60$ after 1-year follow-up. Complications (not further specified), number of treatment related fluctuations (TRFs) and mortality were also recorded.

\section{Statistical analysis}

For statistical analyses we used SPSS software (V.21.0 and V.24.0). Data were expressed as medians with IQR or as proportions. We used Mann-Whitney $\mathrm{U}$ test to compare continuous variables across two groups, and $\chi^{2}$ or Fisher's exact tests to compare proportions. A two-sided $\mathrm{p}<0.05$ was considered statistically significant. We assessed the effect of IVIg on the GBS disability scale at 4 and 26 weeks by a multivariable ordinal regression model, where we corrected for known prognostic and imbalanced factors (age, ataxia, autonomic dysfunction, GBS disability score and MRC sum score at entry, preceding diarrhoea, 


\begin{tabular}{|c|c|c|c|}
\hline & $\begin{array}{l}\text { Supportive } \\
\text { care group } \\
\mathrm{n}=40\end{array}$ & $\begin{array}{l}\text { IVIg group } \\
\mathrm{n}=148\end{array}$ & $P$ value \\
\hline Male, n (\%) & $23(58)$ & $100(68)$ & 0.24 \\
\hline Age, y, median (IQR) & $49(32-58)$ & $46(34-59)$ & 0.79 \\
\hline $\begin{array}{l}\text { Duration from onset to study entry } \\
\text { (days), median (IQR) }\end{array}$ & $6(4-10)$ & $6(3-9)$ & 0.26 \\
\hline $\begin{array}{l}\text { Duration from onset to start } \\
\text { treatment (days), median (IQR) }\end{array}$ & na & $5(3-9)$ & na \\
\hline $\begin{array}{l}\text { Duration from start treatment to } \\
\text { study entry (days), median (IQR) }\end{array}$ & na & $0(0-0)$ & na \\
\hline Region, $n(\%)$ & & & na \\
\hline Europe & $29(73)$ & $101(68)$ & \\
\hline Americas & $5(13)$ & $32(22)$ & \\
\hline Asia & $3(8)$ & $13(9)$ & \\
\hline Africa & $3(8)$ & $0(0)$ & \\
\hline Australia & $0(0)$ & $2(1)$ & \\
\hline \multicolumn{4}{|l|}{ Antecedent event, $\mathrm{n}(\%)$} \\
\hline URTI & $20 / 39(51)$ & $57(39)$ & 0.15 \\
\hline Diarrhoea & $7 / 39(18)$ & $43(29)$ & 0.16 \\
\hline Other & $4 / 39(10)$ & $19(13)$ & 0.66 \\
\hline None & $8 / 39(21)$ & $29(20)$ & 0.90 \\
\hline \multicolumn{4}{|l|}{ Characteristics at entry } \\
\hline Cranial nerve involvement, $\mathrm{n}(\%)$ & $12(30)$ & $52(35)$ & 0.54 \\
\hline Oculomotor & $2(5)$ & $8(5)$ & 1.00 \\
\hline Facial & $10(25)$ & $39(26)$ & 0.86 \\
\hline Bulbar & $2(5)$ & $17(12)$ & 0.23 \\
\hline MRC sum score, median (IQR) & $54(52-57)$ & $54(50-57)$ & 0.41 \\
\hline GBS disability score, n (\%) & & & 0.19 \\
\hline 1: Minor symptoms and capable of & $6(15)$ & $12(8)$ & \\
\hline
\end{tabular}

running

\begin{tabular}{|c|c|c|c|}
\hline $\begin{array}{l}\text { 2: Able to walk } 10 \mathrm{~m} \text { or more without } \\
\text { assistance but unable to run }\end{array}$ & $34(85)$ & $136(92)$ & \\
\hline \multicolumn{4}{|l|}{ GBS clinical variant, $n(\%)$} \\
\hline Sensorimotor & $26(65)$ & $111(75)$ & 0.21 \\
\hline Pure motor & $12(30)$ & $25(17)$ & 0.06 \\
\hline MFS-GBS-overlap & $1(3)$ & $9(6)$ & 0.69 \\
\hline Pharyngeal-cervical-brachial & $1(3)$ & $3(2)$ & 1.00 \\
\hline Sensory deficits, n (\%) & $21(53)$ & $85(57)$ & 0.58 \\
\hline Ataxia, n (\%) & $7 / 39(18)$ & $50 / 139(36)$ & 0.03 \\
\hline Autonomic dysfunction, $\mathrm{n}(\%)$ & $1 / 39(3)$ & $25(17)$ & 0.02 \\
\hline Pain, n (\%) & $22 / 39(56)$ & $78(53)$ & 0.68 \\
\hline \multicolumn{4}{|l|}{ Additional investigation } \\
\hline \multicolumn{4}{|l|}{$\begin{array}{l}\text { Electrophysiological classification } \\
(\mathrm{n}, \%)\end{array}$} \\
\hline Demyelinating & $13 / 32(41)$ & $63 / 121(52)$ & 0.25 \\
\hline Axonal & $1 / 32(3)$ & $3 / 121(3)$ & 1.00 \\
\hline Inexcitable & $0 / 32(0)$ & $0 / 121(0)$ & na \\
\hline Equivocal & $16 / 32(50)$ & $45 / 121(37)$ & 0.19 \\
\hline Normal & $2 / 32(6)$ & $10 / 121(8)$ & 1.00 \\
\hline
\end{tabular}

GBS, Guillain-Barré syndrome; IVIg, intravenous immunoglobulin; MFS, Miller Fisher syndrome; MRC, Medical Research Council; na, not applicable; URTI, upper respiratory tract infection.

electrophysiological subtype and geographical region). We additionally corrected for the presence of early improvement, which for the supportive care group was defined as improving at least two points on the MRC sum score from entry to the first visit after 1 week, and for the IVIg group as improving at least two points on the MRC sum score during the visits prior to and after start of IVIg. The reported ORs expressed the odds of having a lower GBS disability score (hence a better outcome). A KaplanMeier curve was calculated for patients reaching full muscle strength recovery, defined as an MRC sum score of 60 points.

\section{RESULTS}

By January 2017, 1300 patients were enrolled in IGOS with a follow-up period of at least 12 months. We excluded 391 patients (30\%): $71(5 \%)$ with an alternative diagnosis, 6 $(0.4 \%)$ with a protocol violation, $10(1 \%)$ with incomplete data, 189 (15\%) from Bangladesh and 115 (9\%) who had a variant form of GBS without limb weakness (figure 1). Of the remaining 909 patients, 11 (1\%) had a GBS disability score higher than 2 before study entry, and 705 (78\%) had a score greater than 2 at study entry, and they were also excluded. The remaining group of 193 patients who presented with a mild form of GBS were treated as follows: $40(22 \%)$ with supportive care alone, 148 (77\%) with IVIg and $5(3 \%)$ with PE. Patients who underwent PE only were excluded from this study. Thus 188 patients altogether were included (figure 1). The 148 IVIg treated patients received their IVIg course of $2 \mathrm{~g} / \mathrm{kg}$ in $2-5$ days before or at entry of the study $(\mathrm{n}=112,76 \%)$ or in the first week after study entry $(\mathrm{n}=36,24 \%)$.

\section{Patient characteristics}

There were no differences between the groups in age, gender, reported antecedent events, GBS disability score, MRC sum score, GBS variants, cranial nerve involvement or pain at entry (table 1 ).

Compared with the untreated patients, the IVIg group more often had ataxia $(50 / 139,36 \%$ vs $7 / 39,18 \%, p=0.03)$ and autonomic dysfunction $(25 / 142,17 \%$ vs $1 / 39,3 \%$, $\mathrm{p}=0.02)$. The MRC sum score after 1 week of follow-up did not differ between the groups (IVIg group 56, IQR 50-59 vs the supportive care group $56, \mathrm{IQR} 54-58, \mathrm{p}=0.51$ ). However, few patients in the IVIg group improved two points on the MRC sum score prior to and after the start of their IVIg (23/132, 17\%), whereas improvement from study entry to 1 week often occurred in the supportive care group $(14 / 31,45 \%, p=0.001)$. The GBS disability scores deteriorated slightly after 1 week in the intravenous Ig group in which $41 / 135$ (30\%) of the patients had deteriorated at least one point compared with only $5 / 34(15 \%)$ of the supportive care alone patients $(\mathrm{p}=0.07$, figure 2$)$.

\section{Primary endpoint}

Treatment with one IVIg course made no difference to the GBS disability score 4 weeks after study entry (figure 2). After correction for prognostic confounders and unbalanced patient characteristics, the adjusted ORs (aOR) for a better outcome at 4 weeks in the IVIg group was 1.62 (95\% CI 0.63 to 4.13 , $\mathrm{p}=0.32)($ table 2).

\section{Secondary endpoints}

There was no effect on the GBS disability scale at 26 weeks after IVIg. The aOR for a lower GBS disability score at 26 weeks was $0.65(95 \%$ CI 0.24 to $1.78, \mathrm{p}=0.41)$ (table 2). There was also no favourable effect on any of the other secondary endpoints, although fewer IVIg treated patients reported pain after 26 weeks $(26 / 121,22 \%)$ compared with supportive care patients $(12 / 30,40 \%), p=0.04$, table 3$)$. 

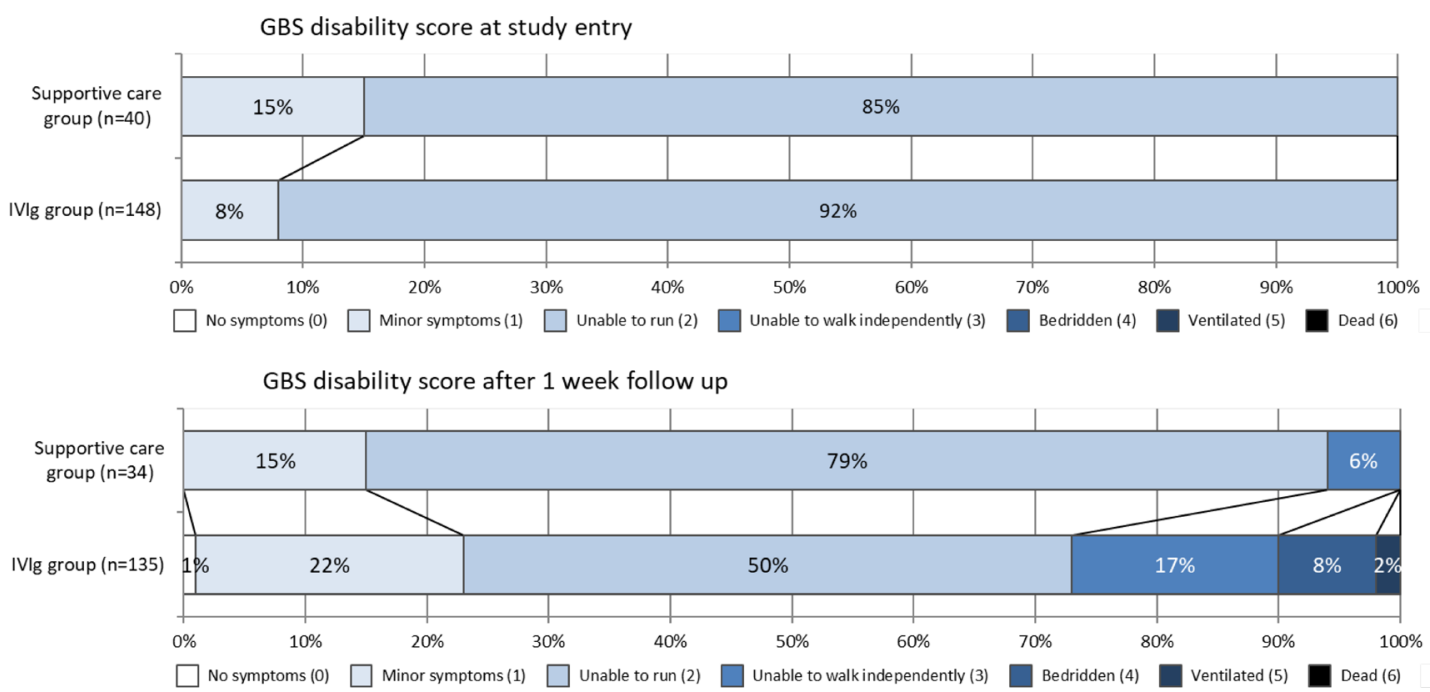

GBS disability score after 4 weeks follow up

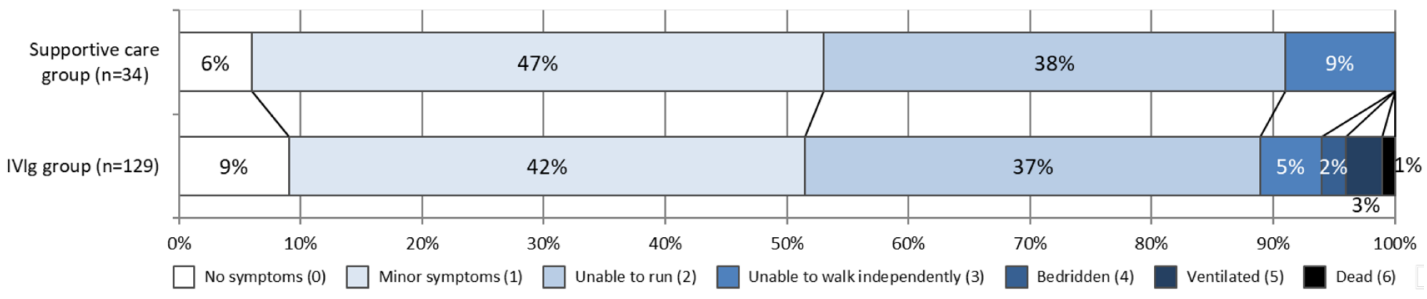

GBS disability score after 26 weeks follow up

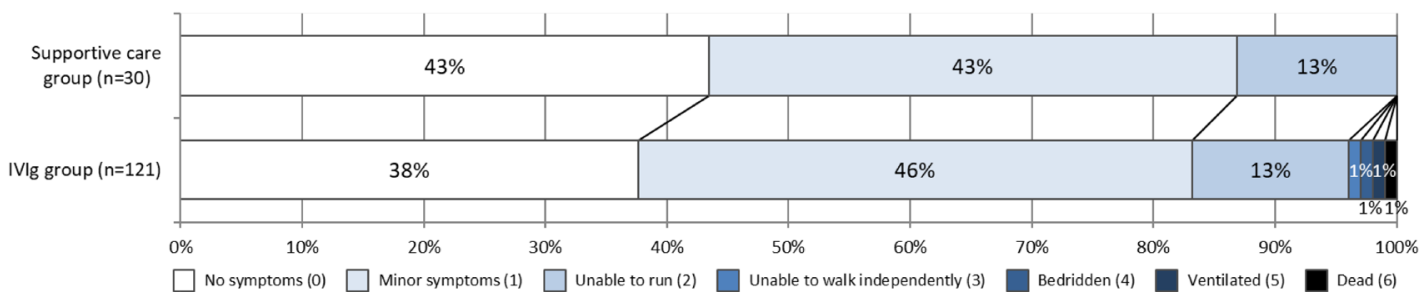

Figure 2 GBS disability score at various time points. GBS, Guillain-Barré syndrome; IVIg, intravenous immunoglobulin.

The median R-ODS centile metric score did not differ between the two groups at 4 weeks (table 3 ). The time to complete muscle strength recovery was shorter in theIVIg group (28 days, IQR 14-56) than in the supportive care group (56 days, IQR $14-182, \mathrm{p}=0.03)$. However, the Kaplan-Meier analysis at 1 -year follow-up did not differ significantly ( $\mathrm{p} \log$ rank $=0.26$, figure $3 \mathrm{~A})$.
Few side effects of IVIg were reported; these included headache $(\mathrm{n}=8)$, nausea/vomiting $(\mathrm{n}=4)$, venous puncture hazards $(n=1)$, eczema $(n=1)$, blood pressure fluctuations $(n=1)$ and thromboembolism $(\mathrm{n}=1)$. Ten patients $(7 \%)$ experienced a TRF of whom six were treated with either a second IVIg course or PE. Five other patients (3\%) received a second IVIg course or additional PE, probably because of ongoing disease progression

Table 2 Unadjusted and adjusted OR for an improved GBS disability score at 4 and 26 weeks

\begin{tabular}{|c|c|c|c|c|c|c|}
\hline & $\mathrm{N}$ & $\begin{array}{l}\text { Unadjusted OR } \\
(95 \% \mathrm{Cl})\end{array}$ & $P$ value & $\mathrm{N}$ & $\begin{array}{l}\text { Adjusted OR* } \\
(95 \% \mathrm{Cl})\end{array}$ & $P$ value \\
\hline \multicolumn{7}{|l|}{ Week 4} \\
\hline Supportive care & 34 & 1.0 (ref.) & & 27 & 1.0 (ref.) & \\
\hline IVlg & 129 & 0.69 (0.33 to 1.43$)$ & 0.32 & 98 & 1.62 (0.63 to 4.13$)$ & 0.32 \\
\hline \multicolumn{7}{|l|}{ Week 26} \\
\hline IVlg & 121 & 0.75 (0.35 to 1.62$)$ & 0.47 & 97 & 0.65 (0.24 to 1.78$)$ & 0.41 \\
\hline
\end{tabular}


Table 3 Clinical outcome at 4 weeks and 26 weeks in patients with an initial mild form of GBS treated with supportive care alone or additional IVIg

\begin{tabular}{|c|c|c|c|}
\hline & $\begin{array}{l}\text { Supportive } \\
\text { care group }\end{array}$ & IVlg group & $P$ value \\
\hline Week 4 & $n=34$ & $n=129$ & \\
\hline GBS disability score, $\mathrm{n}(\%)$ & & & $0.66^{*}$ \\
\hline Healthy (0) & $2(6)$ & $12(9)$ & \\
\hline Minor symptoms (1) & $16(47)$ & $54(42)$ & \\
\hline Able to walk independently (2) & $13(38)$ & $48(37)$ & \\
\hline Able to walk with help (3) & $3(9)$ & $7(5)$ & \\
\hline Bedridden or chairbound (4) & $0(0)$ & $3(2)$ & \\
\hline Ventilated (5) & $0(0)$ & $4(3)$ & \\
\hline Dead (6) & $0(0)$ & $1(1)$ & \\
\hline Improving to GBS disability score $=0, n(\%)$ & $2(6)$ & $12(9)$ & 0.74 \\
\hline $\begin{array}{l}\text { Time needed to reach GBS disability } \\
\text { score }=0 \text { (days), median (IQR) }\end{array}$ & $91(91-274)$ & $91(56-365)$ & 0.64 \\
\hline $\begin{array}{l}\text { Deteriorating to GBS disability score } \geq 3 \\
\text { during first } 4 \text { weeks, } n(\%)\end{array}$ & $3 / 30(10)$ & $42 / 118(36)$ & 0.01 \\
\hline MRC sum score, median (IQR) & $59(58-60)$ & $60(56-60)$ & 0.74 \\
\hline Recovered muscle strength, $\mathrm{n}(\%)$ & $13 / 31(42)$ & $75 / 128(59)$ & 0.09 \\
\hline $\begin{array}{l}\text { Time needed to reach full muscle strength } \\
\text { (days), median (IQR) }\end{array}$ & $56(14-182)$ & $28(14-56)$ & 0.03 \\
\hline $\begin{array}{l}\text { Admitted to hospital or rehabilitation } \\
\text { centre, } n(\%)\end{array}$ & $1(3)$ & $31 / 128(24)$ & 0.01 \\
\hline Cranial nerve deficits, $\mathrm{n}(\%)$ & $8 / 32(25)$ & $33 / 127(26)$ & 0.91 \\
\hline Sensory deficits, n (\%) & $13 / 31(42)$ & $54 / 127(43)$ & 0.95 \\
\hline R-ODS centile metric, median (IQR) $\dagger$ & $71(55-93)$ & $69(52-83)$ & 0.59 \\
\hline Pain, $n(\%)$ & $14 / 33(42)$ & $36 / 128(28)$ & 0.11 \\
\hline FSS, median (IQR) & $44(18-57)$ & $41(27-54)$ & 0.96 \\
\hline EuroQol VAS, median (IQR) & $80(60-90)$ & $70(51-83)$ & 0.38 \\
\hline Week 26 & $n=30$ & $n=121$ & \\
\hline GBS disability score, $n(\%)$ & & & $0.47^{*}$ \\
\hline Healthy (0) & $13(43)$ & $46(38)$ & \\
\hline Minor symptoms (1) & $13(43)$ & $55(46)$ & \\
\hline Able to walk independently (2) & $4(13)$ & $16(13)$ & \\
\hline Able to walk with help (3) & $0(0)$ & $1(1)$ & \\
\hline Bedridden or chairbound (4) & $0(0)$ & $1(1)$ & \\
\hline Ventilated (5) & $0(0)$ & $1(1)$ & \\
\hline Dead (6) & $0(0)$ & $1(1)$ & \\
\hline Improving to GBS disability score $=0, n(\%)$ & $13(43)$ & $46(38)$ & 0.59 \\
\hline MRC sum score, median IQR & $60(60-60)$ & $60(60-60)$ & 0.29 \\
\hline Recovered muscle strength, $\mathrm{n}(\%)$ & $24 / 28(86)$ & 92/117 (79) & 0.60 \\
\hline Admitted to the hospital/rehab, $\mathrm{n}(\%)$ & $0(0)$ & 3/121 (3) & 1.00 \\
\hline Cranial nerve deficits, n (\%) & $2 / 28(7)$ & $11 / 118(9)$ & 1.00 \\
\hline Sensory deficits, n (\%) & $8 / 28(29)$ & $30 / 118(25)$ & 0.73 \\
\hline R-ODS centile metric, median (IQR)‡ & $93(75-100)$ & $93(74-100)$ & 0.96 \\
\hline Pain, n (\%) & $12(40)$ & $26 / 121(22)$ & 0.04 \\
\hline FSS, median (IQR) & $22(9-52)$ & $22(10-42)$ & 0.76 \\
\hline EuroQol VAS, median (IQR) & 90 (83-99) & 90 (75-98) & 0.28 \\
\hline Requiring ventilation, $\mathrm{n}(\%)$ & $0(0)$ & $6(4)$ & 0.35 \\
\hline Mortality, n (\%) & $0(0)$ & $1(1)$ & 1.00 \\
\hline Other endpoints & $n=40$ & $\mathrm{n}=148$ & \\
\hline Residual symptoms after 1 year, $\mathrm{n}(\%)$ & $11 / 29(38)$ & $44 / 107(41)$ & 0.76 \\
\hline \multicolumn{4}{|c|}{$\begin{array}{l}\text { *P value retrieved from unadjusted ordinal regression analysis. } \\
\text { tPatients having at least one answer 'not applicable' on R-ODS at } 4 \text { weeks: } \\
\text { n=57/140 (29\%). } \\
\text { †Patients having at least one answer 'not applicable' on R-ODS at } 26 \text { weeks: } \\
\text { n=34/139 ( } 25 \%) \text {. } \\
\text { FSS, Fatigue Severity Scale; GBS, Guillain-Barré syndrome; IVIg, intravenous } \\
\text { immunoglobulin; MRC, Medical Research Council; rehab, rehabilitation centre; R- } \\
\text { ODS, Rasch-built Overall Disability Scale; VAS, Visual Analogue Scale. }\end{array}$} \\
\hline
\end{tabular}
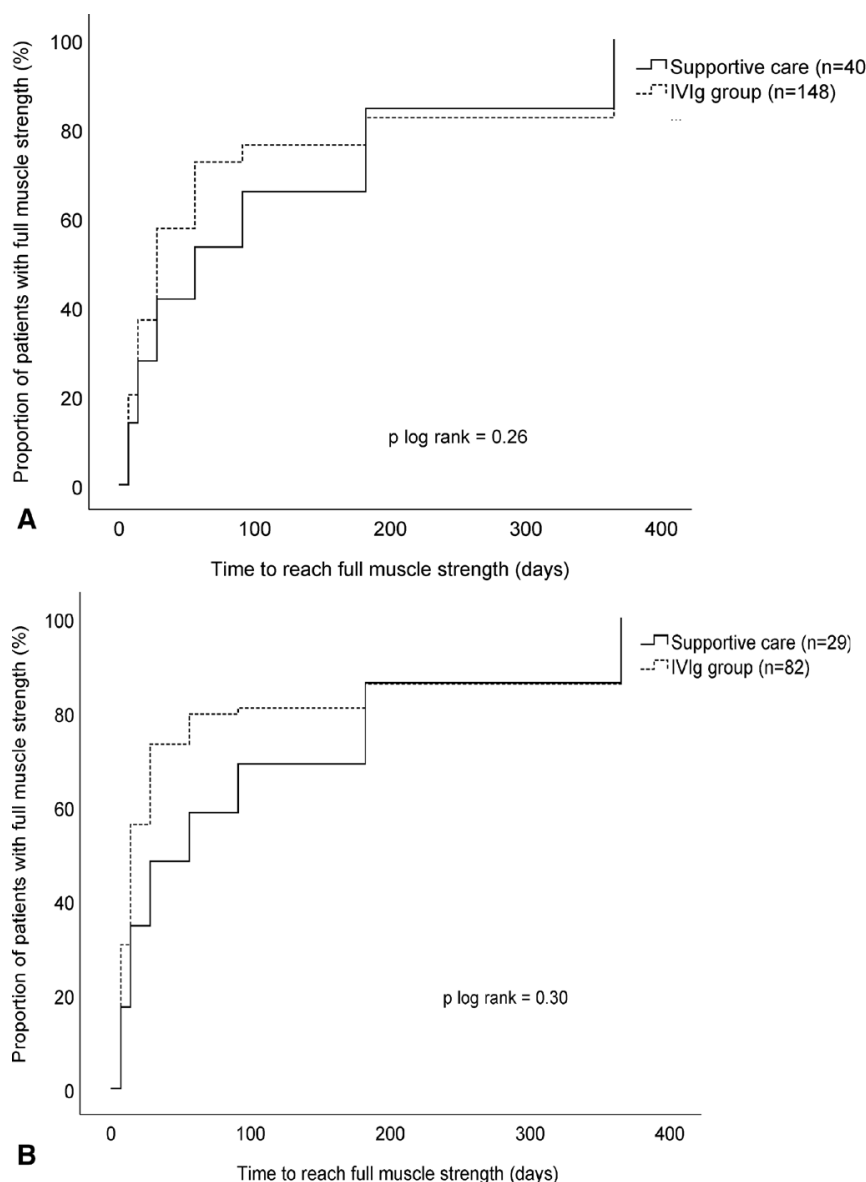

Figure 3 Time to regain full muscle strength in mild GBS patients treated with supportive care versus IVIg in the complete cohort (A) and in the subgroup with persistently mild GBS patients (B). GBS, Guillain-Barré syndrome; IVIg, intravenous immunoglobulin.

despite IVIg. One patient in the IVIg group died 4 weeks from presentation. He was 64 years old, had no medical history, presented with a mild sensorimotor GBS but continued to deteriorate to severe GBS in the first weeks. He received $2 \mathrm{~g} / \mathrm{kg}$ IVIg in 5 days after admission and was retreated with IVIg $0.8 \mathrm{~g} / \mathrm{kg}$ in 2 days after 2 weeks, and died 2 weeks later from bilateral pulmonary thromboembolism and a recent left ventricular myocardial infarction.

After 1-year follow-up, the frequency of residual symptoms was similar in both groups, occurring in 44/107 (41\%) of the IVIg treated patients and in $11 / 29(38 \%)$ of the untreated patients $(p=0.76)$. In the total group, residual symptoms most frequently consisted of pain $(32 / 137,23 \%)$, sensory deficits $(31 / 135,23 \%)$, cranial nerve involvement $(11 / 136,8 \%)$ and limb weakness $(11 / 136,8 \%)$.

\section{Subgroup analysis of patients with persistent mild GBS}

A further analysis was conducted in those patients with persistent mild GBS for the first 2 weeks (GBS disability score 2 or lower), including 29 patients in the supportive care group and 82 patients in the IVIg group. The baseline characteristics were comparable between the two groups and did not differ from the characteristics of the whole group of patients with mild GBS at study entry (online supplemental appendix table 1). With a multivariable ordinal regression model, the aOR for an improved GBS disability score at 4 weeks was 2.32 in favour of IVIg, but this was not significant $(95 \%$ CI 0.76 to $7.13, \mathrm{p}=0.14)$. Most of the 
secondary endpoints did not improve after IVIg. However, more IVIg treated patients regained full muscle strength after 4 weeks $(54 / 77,70 \%$ vs $12 / 25,48 \%, \mathrm{p}=0.04)$ and the time to regain full muscle strength was shorter in the IVIg treated patients (14 days, IQR 7-28) than in the untreated patients (56 days, IQR $14-182, p=0.01)$. However, the Kaplan-Meier curves of the two groups displaying the time to regain full muscle strength after 4 weeks were not different (figure 3B). Residual symptoms were frequently and equally present in both groups (supportive care group 9/26 (35\%) and IVIg group 20/64 (31\%), $\mathrm{p}=0.76)$.

\section{DISCUSSION}

This observational study showed no benefit from IVIg on functional outcome in GBS patients who were able to walk independently at presentation or during the first 2 weeks after study entry. Up to $41 \%$ of IVIg treated and untreated patients showed residual symptoms at 1 year.

We have conducted the first comparative study to estimate the efficacy of IVIg in mild GBS. Because of the observational nature of the study, treatment was offered at the discretion of the study investigator. Approximately three-quarters of patients with persistent mild GBS were treated with IVIg, despite the lack of any controlled trial data providing evidence for efficacy of IVIg in mild GBS. Arguments to treat this group in an early phase are that it is currently not possible to predict who is at risk for further deterioration, early treatment may prevent further nerve damage, and the fact that side effects of a standard IVIg course $(2 \mathrm{~g} / \mathrm{kg}$ in 5 days $)$ are infrequent and generally mild. In the subanalysis of persistent mild GBS, the baseline characteristics were comparable, and so the question arises whether clinicians were inclined to treat mild GBS whatever the circumstances or if there were other unobserved factors that resulted in confounding by indication. This phenomenon occurs when a worse disease course is both an indication to start treatment and also a predictor for poor outcome. Another likely confounder is disease progression, which would have been more likely to lead to IVIg treatment compared with those with a stable course or improvement. Of the untreated patients, 14/31 (45\%) were already improving in the first week after study entry, whereas only 23/132 (17\%) of the IVIg treated patients were improving at the time of starting the intravenous Ig course $(p=0.001)$. Finally, various electrophysiological parameters including compound muscle action potential amplitude have been identified as prognostic factor. ${ }^{23}{ }^{24}$ Although we have corrected for electrophysiological subtypes in the multivariable regression analysis, we have not assessed individual NCS parameters because there was no standardised NCS protocol in IGOS.

We observed that IVIg appears to hasten full muscle strength recovery. This result should be interpreted with care, since this was one positive finding among many secondary endpoints examined. However, it might be argued that the time needed to recover strength is a more responsive endpoint in patients with mild GBS. Previously, a randomised controlled trial showed that two sessions of PE hastened the onset of motor recovery in patients with mild GBS compared with untreated patients. ${ }^{1}$ Clinical deterioration was less frequent in the PE group (4\% vs $39 \%, p=0.0001$ ) in that study, but this was also influenced by the fact that patients who deteriorated were regrouped into a moderate GBS group, receiving two or four PE sessions. The design of that PE trial was suitable for patients with mild GBS, as deterioration would regroup them into a PE group with more PE sessions. For IVIg, this is problematic, because IVIg is given in one standard course over 2-5 days. Unfortunately, we are not able to predict which patients with mild GBS at presentation will deteriorate. Until prognostic markers are identified that predict deterioration in mild GBS patients, a well-designed prospective trial evaluating the efficacy of IVIg in mild GBS remains problematic, primarily because of ethical constraints.

This is the first study evaluating the 1-year outcome in mildly affected GBS patients. Previously, problems with hand and arm function and mobility have been reported in up to $38 \%$ of mild GBS patients at 6 months, irrespective of treatment. ${ }^{6}$ We also found that despite the presumed benign course and good outcome, approximately $40 \%$ of patients with mild GBS, regardless of IVIg treatment, had residual symptoms at a year. In the subset of those with persistent mild GBS, residual symptoms were present in $35 \%$ of patients. This demonstrates the unmet need for more effective treatment even for those considered mildly affected.

The most important limitation of our study is its observational nature resulting in selection bias and confounding by indication. In addition, the most responsive primary endpoint for patients with mild GBS is unknown. As discussed above, onset of motor recovery might be a responsive endpoint, but the IGOS database did not document the date of onset of motor recovery so we could only estimate the time of onset of motor recovery by using the study visit dates. Another possible endpoint might be time to hospital discharge, especially in studies including cost-effectiveness analysis. However, discharge policies differ widely between hospitals and the date of hospital discharge was not recorded in IGOS. For this study, we used the GBS disability scale because it is widely known and most often used in therapeutic trials for GBS. However, the scale may not be sensitive enough for patients with mild GBS. In 2013, a group of inflammatory neuropathy experts reached agreement and recommended using the activity and participation level measured by the 24-item R-ODS for all future therapeutic GBS studies. ${ }^{20} 25$ However, the R-ODS scale contains items which are not always applicable, especially in different regions of the world, diminishing its reliability and applicability. ${ }^{26}$ Lastly, although IGOS has collected a very large cohort of GBS patients, the patient numbers in this study, and especially in the substudy of patients with persistent mild GBS, were small, and the study could be underpowered.

Although this observational study did not identify significant benefit from adding IVIg to supportive care in initially mild GBS, confounding factors may have masked the possible positive effect of such treatment. IVIg may shorten time to full recovery of muscle strength and PE has previously been proven to hasten recovery in mild GBS. ${ }^{1}$ Since other trials in severe GBS have shown that IVIg and PE have similar efficacy, ${ }^{7}$ it would be premature to conclude that PE is more efficacious than IVIg in mild GBS. Because this study has shown that $40 \%$ of patients with mild GBS have persistent symptoms at 1 year regardless of treatment status, other more effective treatments are needed. Ideally, future studies would use more responsive clinical outcome measures appropriate for mild GBS, measure prognostic biomarkers of ongoing inflammation and nerve damaging which predict disease progression, and include more participants in a randomised controlled design.

\section{Author affiliations}

${ }^{1}$ Department of Neurology, Erasmus MC, Rotterdam, The Netherlands

${ }^{2}$ Department of Neurology, Aarhus University Hospital, Aarhus, Denmark

${ }^{3}$ Department of Neurology, Johns Hopkins University, Baltimore, Maryland, USA 
${ }^{4}$ Centre for Neuromuscular Disease, National Hospital for Neurology and Neurosurgery, London, UK

${ }^{5}$ Department of Neurology, St. Elizabeth's Medical Center, Boston, Massachusetts, USA

${ }^{6}$ Department of Neurology, Instituto de Investigaciones Neurológicas Raúl Carrea, FLENI, Buenos Aires, Argentina

${ }^{7}$ Department of Neurology, Chiba University, Chiba, Japan

${ }^{8}$ Department of Neurology, University Hospital of Modena, Modena, Italy

${ }^{9}$ Department of Neurology, University Hospital of Cologne, Cologne, Germany

${ }^{10}$ Department of Neurology, Kindai University, Osaka, Japan

11Department of Neurology, Hospital Britanico, Buenos Aires, Argentina

${ }^{2}$ Department of Neurology, University Milano-Bicocca, Monza, Italy

${ }^{13}$ Department of Immunology, Erasmus MC, Rotterdam, The Netherlands

\section{Acknowledgements We thank all patients who participated in this long term} follow-up study.

Collaborators For this study, patients were selected from the following collaborators: H. Andersen, MD, PhD (Aarhus University Hospital, Aarhus, Denmark);S. Attarian, MD, PhD (CHU Timone, Marseille, France);U.A. Badrising, MD, PhD (Leiden University Medical Centre, Leiden, The Netherlands);K. Bateman, MD, PhD (Groote Schuur Hospital, Cape Town, South-Africa);L. Benedetti, MD, PhD (Ospedale Sant' Andrea La Spezia, La Spezia, Italy);B. van den Berg, MD (Franciscus Gasthuis, Rotterdam, The Netherlands):P. Van den Bergh, MD, PhD (University Clinic St. Luc, Leuven, Belgium); T.E. Bertorini, MD (The University of Tennessee Health Science Center (UTHSC), Memphis, USA);R. Bhavaraju-Sanka, MD (University Hospital/ University of Texas Health Science Center, San Antonio Texas, USA); M. Bianco (Milan University, Humanitas Clinicala and Research Institute Milan, Italy);C. Briani, MD (University of Padova, Padova, Italy);J. Bürmann, MD (Universitätsklinikum des Saarlandes, Homburg, Germany); C. Casasnovas, MD, PhD (Bellvitge University Hospital - IDIBELL Neurometabolic Diseases Group. CIBERER, Barcelona, Spain); C.C. Chao, MD, PhD (National Taiwan University Hospital, Taipei, Taiwan); G. Chavada, MD, PhD (Glasgow University, Glasgow, UK);K.G. Claeys, MD, PhD (1. University Hospitals Leuven, Leuven, Belgium, 2. KU Leuven, Leuven, Belgium);J.S. Cosgrove, MD (Leeds General Infirmary, Leeds, UK):M.C. Dalakas, MD (1. Thomas Jefferson University, Philadelphia, USA, 2. National and Kapodistrian University of Athens, Athens, Greece); A. Davidson, MD (University of Glasgow, Glasgow, UK); G.W. van Dijk, MD (Canisius Wilhelmina Hospital, Nijmegen, The Netherlands); E. Dardiotis, MD (University of Thessaly, Hospital of Larissa, Larissa, Greece); M. Derejko, MD (Odense University Hospital, Odense, Denmark);M.M. Dimachkie, MD (University of Kansas Medical Center, Kansas City, USA);C. Dornonville de la Cour, MD (National Hospital Copenhagen, Copenhagen, Denmark);A. Echaniz-Laguna, MD (Bicêtre University Hospital, Paris, France); F. Eftimov, MD, PhD (Amsterdam University Medical Centre, Amsterdam, The Netherlands);C.G. Faber, MD, PhD (Maastricht University Medical Centre, Maastricht, The Netherlands);R. Fazio, MD (Scientific Institute San Raffaele, Milan, Italy);J. Fehmi (University of Oxford E.A. Fulgenzi, MD (Hospital Cesar Milstein Buenos Aires, Buenos Aires, Argentina);T. García-Sobrino, MD (Hospital Clínico de Santiago, Santiago de Compostela (A Coruña), Spain);C.J. Gijsbers, MD (Vlietland Hospital, Schiedam, The Netherlands); V. Granit, MD (Montefiore Medical, Center, New York, USA):S. Grisanti, MD (Ospedale Sant' Andrea La Spezia, La Spezia, Italy);G. Gutiérrez-Gutiérrez, MD (Hospital Universitario Infanta Sofia, San Sebastian, Spain);J. V. Holbech, MD, PhD (Odense University Hospital, Odense, Denmark);J.K.L. Holt, PhD, FRCP (The Walton Centre, Liverpool, UK);C. Homedes, MD (Bellvitge University Hospital - IDIBELL Neurometabolic Diseases Group. CIBERER, Barcelona, Spain);B. Islam, MD, PhD (International Centre for Diarrhoeal Disease Research, Bangladesh (icddr,b), Dhaka, Bangladesh);Z. Islam, MD, PhD (International Centre for Diarrhoeal Disease Research, Bangladesh (icddr,b), Dhaka, Bangladesh);I. Jahan, PhD candidate (International Centre for Diarrhoeal Disease Research, Bangladesh (icddr,b), Dhaka, Bangladesh);I. Jericó Pascual, MD, PhD (Complejo Hospitalario de Navarra, Pamplona, Spain);S. Karafiath, MD (University of Utah School of Medicine, Salt Lake City, USA);H. Kerkhoff, MD, PhD (Albert Schweitzer Hospital, Dordrecht, The Netherlands); K. Kimpinski, MD (University Hospital, LHSC, London-Ontario, Canada); A. Kohler, MD (Instituto de Investigaciones Neurológicas Raúl Carrea, FLENI, Buenos Aires, Argentina);N. Kolb, MD (University of Vermont, Burlington VT, USA); K. Kuitwaard, MD, PhD (1. Albert Schweitzer Hospital, Dordrecht, 2. Erasmus MC, Rotterdam, The Netherlands); M. Kuwahara, MD, PhD (Kindai University, Osaka, Japan);S.S. Ladha, MD (Barrow Neurology Clinics, Phoenix, Arizona, USA);E. Lee Pan, MBChB (Groote Schuur Hospital, Cape Town, South-Africa);G.A. Marfia, MD (Neurological Clinic, Policlinico Tor Vergata, Rome, Italy);A. Magot, MD (Reference Centre for NMD, Nantes University Hospital, France);C. Márquez Infante, MD (Hospital Universitario Virgen del Rocio, Seville, Spain);L. Martín-Aguilar, MD (Hospital de la Santa Creu i Sant Pau, Universitat Autònoma de Barcelona, Barcelona, Spain); E. Martinez Hernandez, MD (Institut d'Investigacions Biomèdiques August Pi i Sunyer (IDIBAPS), Hospital Clinic, Barcelona, Spain); G. Mataluni, MD, PhD (Neurological Clinic, Policlinico Tor Vergata, Rome, Italy);G. Meekins, MD, (University of Minnesota, USA); J.A.L. Miller, MD, PhD (Royal Victoria Infirmary, Newcastle, UK);M.S. Monges, MD (Hospital de Pediatría J.P. Garrahan, Buenos Aires, Argentina);E. Nobile Orazio, MD, PhD (Milan University, Humanitas Clinicala and
Research Institute Milan, Italy);A. Pardal, MD (Hospital Britanico, Buenos Aires, Argentina);J. Pardo Fernandez (Hospital Clínico de Santiago, Santiago de Compostela (A Coruña), Spain); Y. Péréon, MD, PhD (Reference Centre for NMD, Nantes University Hospital, France);M. Pulley, MD (University of Florida, Jacksonville, USA); L. Querol Gutierrez, MD, PhD (Hospital de la Santa Creu i Sant Pau, Universitat Autònoma de Barcelona, Barcelona, Spain);S.W. Reddel, MD, PhD (Concord Repatriation General Hospital, Sydney, Australia);T. van der Ree, MD (Westfriesgasthuis, Hoorn, The Netherlands):S. Rinaldi, MBChB, PhD (University of Oxford J.P.A. Samijn, MD (Maasstad Hospital, Rotterdam, The Netherlands);M. Samukawa, MD, PhD (Kindai University, Osaka, Japan);L. Santoro, MD, PhD (University Federico II, Napels, Italy);A. Savransky, MD, PhD (Hospital de Pediatría J.P. Garrahan, Buenos Aires, Argentina);L. Schwindling, MD (Universitätsklinikum des Saarlandes, Homburg, Germany);M.J. Sedano Tous, MD (Hospital Universitario Marques de Valdecilla, Santander, Cantabria, Spain); Y. Sekiguchi, MD, PhD (Chiba University, Chiba, Japan);N. Shahrizaila, MD (Neurology Unit, Department of Medicine, Faculty of Medicine, University of Malaya, Malaya); N.J. Silvestri, MD (Buffalo Jacobs School of Medicine S. Sindrup, MD, PhD (Odense University Hospital, Odense, Denmark);C.L. Sommer, MD (Universitätsklinikum Würzburg, Würzburg, Germany);A. Spyropoulos (Royal Victoria Infirmary, Newcastle, UK);B. Stein, MD (St. Joseph's Regional Medical Center, Paterson, USA);C.Y. Tan, MRCP (Neurology Unit, Department of Medicine, Faculty of Medicine, University of Malaya, Malaya); H. Tankisi, MD, PhD (Aarhus University Hospital, Aarhus, Denmark); F. Vermeij, MD (Franciscus Gasthuis, Rotterdam, The Netherlands):M.V. Vytopil, MD, PhD (Tufts University School of Medicine Lahey Hospital P.W. Wirtz, MD, PhD (HagaZiekenhuis, The Hague, The Netherlands);W. Waheed, MD (University of Vermont Medical Center, Burlington, USA). Other collaborators were:J.M. Addington, MD (University of Virginia, Charlottesville, USA);S. Ajroud-Driss, MD (Northwestern University Feinberg, Chicago, USA); G. Antonini, MD (Mental Health and Sensory Organs (NESMOS), Sapienza University, Sant'Andrea Hospital, Rome, Italy);I.R. Bella, MD (University of Mass Medical School, Worcester, USA);T.H. Brannagan, MD (Columbia University, New York City, USA);C. Bunschoten, MD, PhD candidate (Erasmus University Medical Centre, Rotterdam, The Netherlands);M. Busby, MD (Leeds General Infirmary, Bradford, UK);S. Butterworth, MD (Pinderfields Hospital, Wakefield, UK);M.E. Conti, MD (University Hospital Clinicas, Buenos Aires, Argentina);S. Chen, MD, PhD (Rutgers, Robert Wood Johnson University Hospital, New Brunswick, USA);A. Doets, MD, PhD candidate (Erasmus University Medical Centre, Rotterdam, the Netherlands);T.E. Feasby, MD (University of Calgary, Calgary, Canada);C. Fokke, MD (Gelre Hospital, Zutphen and Apeldoorn, The Netherlands); T. Fujioka, MD (Toho University Medical Center, Tokyo, Japan);M.P.J. Garssen, MD, PhD (Jeroen Bosch Hospital, 's Hertogenbosch, The Netherlands);J.M. Gilchrist, MD (Soulthern Illinois University School of Medicine, Springfield, USA);J. Gilhuis, MD, PhD (Reinier de Graaf Gasthuis, Delft, The Netherlands); J.M. Goldstein, MD (Yale University School of Medicine, New Haven, USA); N. A. Goyal, MD (University of California, Irvine, USA);R.D.M. Hadden, MD, PhD (King's College Hospital, London, UK);S.T. Hsieh, MD, PhD (National Taiwan University Hospital, Taipei, Taiwan);M. Htut, MD (St. George's Hospital, London, UK);I. Illa, MD, PhD (Hospital de la Santa Creu i Sant Pau, Universitat Autònoma de Barcelona, Barcelona, Spain); K. Jellema, MD, PhD (Haaglanden Medisch Centrum, The Hague, The Netherlands); K. Kaida, MD, PhD (National Defense Medical College, Saitama, Japan);H.D. Katzberg, MD (University of Toronto, Toronto, Canada);L. Kiers, MD (University of Melbourne, Royal Melbourne Hospital, Parkville, Australia);N. Kokubun, MD (Dokkyo Medical University, Tochigi, Japan); R. van Koningsveld, MD, PhD (Elkerliek Hospital, Helmond and Deurne, The Netherlands); A.J. van der Kooi, MD, PhD (Amsterdam University Medical Centre, Amsterdam, The Netherlands);J.Y. Kwan, MD (University of Maryland School of Medicine, Baltimore, USA);L. Landschoff Lassen, MD (Glostrup Hospital, Glostrup, Denmark);V. Lawson, MD (Wexner Medical Center at The Ohio State University, Columbus, USA);S.E. Leonhard, MD, PhD candidate (Erasmus University Medical Centre, Rotterdam, the Netherlands); $M$. Mandarakas, MD, PhD (Erasmus University Medical Centre, Rotterdam, the Netherlands);H. Manji, MD, FRCP (Ipswich Hospital, Ipswich, UK);M.G. Mattiazzi, MD (Hospital Militar Central, Buenos Aires, Argentina);C.J. McDermott, MD (Royal Hallamshire Hospital, NIHR Clinical, Sheffield, UK);Q.D. Mohammad, MD, PhD (National Institute of Neurosciences and Hospital, Dhaka, Bangladesh); G. Morís de la Tassa, MD (Hospital UniversitarioCentral de Asturias, Asturias, Spain);C. Nascimbene, MD, PhD (Luigi Sacco Hospital, Milan, Italy);E.H. Niks, MD, PhD (Leiden University Medical Centre, Leiden, The Netherlands); R.J. Nowak, MD (Yale University School of Medicine, New Haven, USA);M. Osei-Bonsu, MD, PhD (James Cook University Hospital, Middlesbrough, UK);R.M. Pascuzzi, MD (University of Indiana School of Medicine, Indianapolis, USA);R.C. Roberts, MD (Addenbrooke's Hospital Cambridge, Cambridge, UK);I. Rojas-Marcos, MD (Hospital Univesitario Reina Sofia, Cordoba, Spain);J. Roodbol, MD, PhD candidate (Erasmus University Medical Centre, Rotterdam, the Netherlands);S.A. Rudnicki, MD (University of Arkansas, Fayetteville, USA);G.M. Sachs, MD (University of Rhode Island, Providence, USA);A. Schenone, MD, PhD (1. Department of Neurosciences, Rehabilitation, Ophthalmology, Genetics and Maternal and Infantile Sciences (DINOGMI), University of Genova, Genova, Italy 2. IRCCS Policlinico San Martino, Genova, Italy);K. Sheikh, MD, PhD (The University of Texas Health Science Center at Houston, Houston, USA);P. Twydell, DO (Spectrum Health System, Grand Rapids, USA);P. Van Damme, MD, PhD (University Hospital Leuven, Leuven, Belgium);J.D. Varrato, DO (Lehigh Valley Health Network, Allentown, 
USA);L.H. Visser, MD, PhD (Elisabeth-TweeSteden Hospital, Tilburg and Waalwijk, The Netherlands); H.J. Willison, MD, PhD (University of Glasgow, Glasgow, UK);M. van Woerkom (Erasmus MC, Rotterdam, the Netherlands); L. Zhou, MD, PhD (Icahn School of Medicine at Mount Sinai, New York, USA);S.A. Zivkovich, MD, PhD (University of Pittsburgh Medical Center, Pittsburgh, USA).

Contributors CV: Study concept and design, patient inclusion, acquisition of data, analysis and interpretation of the data, drafted and revised the manuscript for intellectual content. Member of IGOS Coordinating Center, IGOS Country Coordinator. TH: Study concept and design, patient inclusion, acquisition of data, interpretation of the data, drafted and revised the manuscript for intellectual content. IGOS Country Coordinator. DRC: Study concept and design, interpretation of the data, drafted and revised the manuscript for intellectual content. Member of the IGOS Steering Committee. RACH: Study concept and design, interpretation of the data, drafted and revised the manuscript for intellectual content. Member of the IGOS Steering Committee. PAvD: Study concept and design, interpretation of the data, drafted and revised the manuscript for intellectual content. Member of the IGOS Steering Committee. FB: Patient inclusion, acquisition of data, interpretation of the data, revised the manuscript for intellectual content. SK: Patient inclusion, acquisition of data, interpretation of the data, revised the manuscript for intellectual content. IGOS Country Coordinator. GG: Patient inclusion, acquisition of data, interpretation of the data, revised the manuscript for intellectual content. SK: Patient inclusion, acquisition of data, interpretation of the data, revised the manuscript for intellectual content. IGOS Country Coordinator. HCL: Patient inclusion, acquisition of data, interpretation of the data, revised the manuscript for intellectual content. RCR: Patient inclusion, acquisition of data, interpretation of the data, revised the manuscript for intellectual content. IGOS Country Coordinator. GC: Patient inclusion acquisition of data, interpretation of the data, revised the manuscript for intellectual content. DB: Patient inclusion, acquisition of data, interpretation of the data, revised the manuscript for intellectual content. MPL: Patient inclusion, acquisition of data, interpretation of the data, revised the manuscript for intellectual content. KCG: Interpretation of the data, revised the manuscript for intellectual content. Member of the IGOS Steering Committee, IGOS Country Coordinator. BCJ: Study concept and design, patient inclusion, acquisition of data, interpretation of the data, drafted and revised the manuscript for intellectual content. Member of the IGOS Steering Committee, Member of the IGOS Coordinating Center, IGOS Country coordinator.

Funding This study is mainly funded by the Interlaken Leadership Awards 2014 from CSL Behring (ILA-2014, https://www.interlakenleadershipawards.com/pastrecipients.aspx). Other sponsors of IGOS are the GBS-CIDP Foundation International, grifols, GAIN Charity, Erasmus University Medical Centre, Glasgow University, CSL Behring and Annexon.

Competing interests DRC is a consultant to Amgen, Annexon Biosciences, argenx SE, Biotest Pharmaceuticals, Boehringer Ingelheim, Cigna Health Management, CSL Behring, Grifols S.A., Neuropore, New Enterprise Associates, Octapharma AG, Passage Bio, Pfizer, Pharnext SAS, Polyneuron Pharmaceuticals, Sanofi-Aventis, Seattle Genetics and UCB Pharma. He is on Data Safety Monitoring Boards for Alnylam Pharmaceuticals, Anavex Life Sciences, PledPharma AB, Momenta Pharma, Hansa Medical AB and Mitsubishi Tanabe Pharma Corporation. He receives royalties for Technology Licensing from AstraZeneca Pharmaceuticals, LP, Genentech, Levicept, Seattle Genetics, Merrimack Pharmaceuticals, Disarm Therapeutics. RACH has consultancies with Hansa Biopharma, Immunic and Sanofi. PAvD has received honoraria for consulting, lectures and serving on steering committees from Octapharma, Kedrion, CSL Behring, Grifols and Hansa (all honoraria to departmental research fund) and received grants from the Prinses Beatrix Spierfonds, Sanquin Blood supply, Shire and Grifols for conducting clinical trials in GBS and CIDP. MPL is supported by the by the National Institute for Health Research University College London Hospitals Biomedical Research Centre. KCG has consulting agreements with Annexon, Argenx and UCB Pharma. BCJ has received funding for research projects from Prinses Beatrix Spierfonds, Horizon 2020, GBS-CIDP Foundation International, Grifols, CSL Behring, Annexon and Hansa Biopharma. He is on the Medical Advisory Board for the GBS-CIDP Foundation International, and a member of the Inflammatory Neuropathy Consortium

Patient consent for publication Not required.

Ethics approval The study was approved by the review boards of the Erasmus University Medical Centre, Rotterdam, the Netherlands, and the local institutional review boards of participating hospitals or universities.

Provenance and peer review Not commissioned; externally peer reviewed.

Data availability statement Data are available on reasonable request. Data collected in IGOS will be used initially for planned research projects conducted by the IGOS Consortium. Some data will be made available from the corresponding author on reasonable request.

Supplemental material This content has been supplied by the author(s). It has not been vetted by BMJ Publishing Group Limited (BMJ) and may not have been peer-reviewed. Any opinions or recommendations discussed are solely those of the author(s) and are not endorsed by BMJ. BMJ disclaims all liability and responsibility arising from any reliance placed on the content. Where the content includes any translated material, BMJ does not warrant the accuracy and reliability of the translations (including but not limited to local regulations, clinical guidelines, terminology, drug names and drug dosages), and is not responsible for any error and/or omissions arising from translation and adaptation or otherwise.

Open access This is an open access article distributed in accordance with the Creative Commons Attribution Non Commercial (CC BY-NC 4.0) license, which permits others to distribute, remix, adapt, build upon this work non-commercially, and license their derivative works on different terms, provided the original work is properly cited, appropriate credit is given, any changes made indicated, and the use is non-commercial. See: http://creativecommons.org/licenses/by-nc/4.0/.

\section{ORCID iDs}

Christine Verboon http://orcid.org/0000-0003-1086-6679

Thomas Harbo http://orcid.org/0000-0003-2178-6076

Richard A C Hughes http://orcid.org/0000-0001-5251-3797

Michael P Lunn http://orcid.org/0000-0003-3174-6027

Satoshi Kuwabara http://orcid.org/0000-0002-4716-8578

Helmar C Lehmann http://orcid.org/0000-0001-6205-2293

Susumu Kusunoki http://orcid.org/0000-0002-1584-8704

Bart C Jacobs http://orcid.org/0000-0002-8985-2458

\section{REFERENCES}

1 Appropriate number of plasma exchanges in Guillain-Barré syndrome. The French Cooperative group on plasma exchange in Guillain-Barré syndrome. Ann Neurol 1997;41:298-306.

2 Doets AY, Verboon C, van den Berg B, et al. Regional variation of Guillain-Barré syndrome. Brain 2018;141:2866-77.

3 Al-Hakem H, Sindrup SH, Andersen H, et al. Guillain-Barré syndrome in Denmark: a population-based study on epidemiology, diagnosis and clinical severity. J Neurol 2019;266:440-9

4 Verboon C, van Doorn PA, Jacobs BC. Treatment dilemmas in Guillain-Barré syndrome. J Neurol Neurosurg Psychiatry 2017;88:346-52.

5 Green DM, Ropper AH. Mild Guillain-Barré syndrome. Arch Neurol 2001;58:1098-101.

6 Van Koningsveld R, Schmitz PIM, Ang CW, et al. Infections and course of disease in mild forms of Guillain-Barré syndrome. Neurology 2002;58:610-4.

7 Hughes RAC, Swan AV, van Doorn PA. Intravenous immunoglobulin for Guillain-Barré syndrome. Cochrane Database Syst Rev 2014:CD002063.

8 Raphael JC, Chevret S, Hughes RA. Plasma exchange for Guillain-Barre syndrome. Cochrane Database Syst Rev 2012;7:CD001798.

9 Hughes RAC. Guillain-Barré syndrome: looking back... and forward. J Neurol Neurosurg Psychiatry 2020;91:111-2.

10 Doets AY, Hughes RA, Brassington R, et al. Pharmacological treatment other than corticosteroids, intravenous immunoglobulin and plasma exchange for Guillain-Barré syndrome. Cochrane Database Syst Rev 2020;1:CD008630.

11 Hughes RAC, Swan AV, Raphaël J-C, et al. Immunotherapy for Guillain-Barré syndrome: a systematic review. Brain 2007;130:2245-57.

12 Abbas A, Rajabally YA. Complications of immunoglobulin therapy and implications for treatment of inflammatory neuropathy: a review. Curr Drug Saf 2019;14:3-13.

13 Verboon C, Doets AY, Galassi G, et al. Current treatment practice of Guillain-Barré syndrome. Neurology 2019;93:e59-76.

14 Jacobs BC, van den Berg B, Verboon C, et al. International Guillain-Barré syndrome outcome study: protocol of a prospective observational cohort study on clinical and biological predictors of disease course and outcome in Guillain-Barré syndrome. $J$ Peripher Nerv Syst 2017;22:68-76.

15 Fokke C, van den Berg B, Drenthen J, et al. Diagnosis of Guillain-Barré syndrome and validation of Brighton criteria. Brain 2014;137:33-43.

16 Kleyweg RP, van der Meché FG, Schmitz PI. Interobserver agreement in the assessment of muscle strength and functional abilities in Guillain-Barré syndrome. Muscle Nerve 1991;14:1103-9.

17 Hadden RD, Cornblath DR, Hughes RA, et al. Electrophysiological classification of Guillain-Barré syndrome: clinical associations and outcome. plasma Exchange/ Sandoglobulin Guillain-Barré syndrome trial group. Ann Neurol 1998;44:780-8.

18 Chevret S, Hughes RA, Annane D. Plasma exchange for Guillain-Barré syndrome. Cochrane Database Syst Rev 2017;2:CD001798.

19 Hughes RA, Brassington R, Gunn AA, et al. Corticosteroids for Guillain-Barré syndrome. Cochrane Database Syst Rev 2016;10:CD001446.

20 van Nes SI, Vanhoutte EK, van Doorn PA, et al. Rasch-built overall disability scale (R-ODS) for immune-mediated peripheral neuropathies. Neurology 2011;76:337-45.

21 van Nes SI, Vanhoutte EK, Faber CG, et al. Improving fatigue assessment in immunemediated neuropathies: the modified Rasch-built fatigue severity scale. J Peripher Nerv Syst 2009;14:268-78.

22 Brooks R. EuroQol: the current state of play. Health Policy 1996;37:53-72.

23 Cornblath DR, Mellits ED, Griffin JW, et al. Motor conduction studies in Guillain-Barré syndrome: description and prognostic value. Ann Neurol 1988;23:354-9. 
24 van den Berg B, Walgaard C, Drenthen J, et al. Guillain-Barré syndrome: pathogenesis, diagnosis, treatment and prognosis. Nat Rev Neurol 2014;10:469-82.

25 Vanhoutte EK, Faber CG, Merkies ISJ, et al. 196th ENMC International workshop: outcome measures in inflammatory peripheral neuropathies
8-10 February 2013, Naarden, the Netherlands. Neuromuscul Disord 2013:23:924-33.

26 Mandarakas M. Modification of the I-RODS to assess outcome of Guillain-Barré syndrome using the IGOS cohort. 2019 peripheral nerve Society meeting. Genoa, Italy, 2019 